\title{
Witches' broom resistant genotype CCN51 shows greater diversity of symbiont bacteria in its phylloplane than susceptible genotype catongo
}

\author{
Juliano Oliveira Santana ${ }^{1}$, Karina Peres Gramacho², Katiúcia Tícila de Souza Eduvirgens Ferreira', \\ Rachel Passos Rezende ${ }^{1}$, Pedro Antônio Oliveira Mangabeira', Ricardo Pedro Moreira Dias³, \\ Francisco M. Couto ${ }^{4}$ and Carlos Priminho Pirovani ${ }^{{ }^{*}}$
}

\begin{abstract}
Background: Theobroma cacao L. (cacao) is a perennial tropical tree, endemic to rainforests of the Amazon Basin. Large populations of bacteria live on leaf surfaces and these phylloplane microorganisms can have important effects on plant health. In recent years, the advent of high-throughput sequencing techniques has greatly facilitated studies of the phylloplane microbiome. In this study, we characterized the bacterial microbiome of the phylloplane of the catongo genotype (susceptible to witch's broom) and CCN51 (resistant). Bacterial microbiome was determined by sequencing the V3-V4 region of the bacterial 16S rRNA gene.

Results: After the pre-processing, a total of 1.7 million reads were considered. In total, 106 genera of bacteria were characterized. Proteobacteria was the predominant phylum in both genotypes. The exclusive genera of Catongo showed activity in the protection against UV radiation and in the transport of substrates. CCN51 presented genus that act in the biological control and inhibition in several taxonomic groups. Genotype CCN51 presented greater diversity of microorganisms in comparison to the Catongo genotype and the total community was different between both. Scanning electron microscopy analysis of leaves revealed that on the phylloplane, many bacterial occur in large aggregates in several regions of the surface and isolated nearby to the stomata.

Conclusions: We describe for the first time the phylloplane bacterial communities of T. cacao. The Genotype CCN51, resistant to the witch's broom, has a greater diversity of bacterial microbioma in comparison to Catongo and a greater amount of exclusive microorganisms in the phylloplane with antagonistic action against phytopathogens.
\end{abstract}

Keywords: Theobroma cacao, Leaf, Microbiome, Diversity

\section{Background}

The phylloplane alone represents the largest biological surface on Earth, outnumbering the cells of the plants themselves $[1,2]$. The microorganisms that live in this region multiply and occupy newly formed niches while the leaves are expanding [2,3]. They are influenced by sunlight and the plants metabolism that have nutrients,

\footnotetext{
* Correspondence: pirovanicp@gmail.com

${ }^{1}$ Department of Biological Science, State University of Santa Cruz, Ilhéus, Bahia, Brazil

Full list of author information is available at the end of the article
}

including carbohydrates, organic acids and amino acids $[4,5]$. Furthermore, the cuticle reduces water evaporation as well as leaching the metabolites in the leaves, resulting in a favorable environment [6-8]. These surfaces are an open environment that receive migrants transferred by various mechanisms including rain, animals and deposition of aerial particles, which contributes to a large microbial diversity $[2,9]$.

The phylloplane microorganisms can be shared randomly among its neighbors, but their survival and presence is generally regulated by the plant [10]. Furthermore, a theory 
proposes a possible transfer of microorganisms through generations [11]. However, this whole microbiome can be affected by environmental factors, including radiation [12] and pollution [13], as well as biotic factors such as leaf age and the presence of other microorganisms [14].

The microbiome present in the phylloplane includes a diversity of bacteria, fungi, yeasts, algae and other microorganisms that have commensal, pathogenic and mutualistic interactions with the plant $[2,15,16]$. Bacteria are numerically dominant in the phylloplane environment, of which a large part are proteobacteria, actinobacteria and bacteroidetes $[9,15,17-22]$. This variation is observed in different species of plants that have characteristic communities of bacteria in the phylloplane, varying between genotypes [23, 24], as well as between species and taxonomic classifications [17].

The microbial activities in the leaves can significantly influence the plant health [25-27]. The nitrogen fixation in the phylloplane is the main mechanism for the addition of nitrogen in tropical humid ecosystems [28] and temperate forests [29]. Plants can still be affected by the production of growth hormones [27] and indirect protection against pathogens $[3,25,30]$. In this environment, the cuticle [8] and the trichomes [31, 32] are also considered defense components in the phylloplane that together with the microorganisms, constitute a complex region [33, 34].

Next-generation sequencing technology (NGS) had a great impact in the microbial genomics field $[35,36]$. The method provides new insights into the non-cultivable microorganisms and the complex host-microbe interactions $[19,37]$. In this approach, the metagenomics used a hypervariable region of the highly conserved $16 \mathrm{~S}$ rRNA gene as a phylogenetic marker allowing the characterization of the diversity of organisms of the total microbiota found in a given habitat $[9,20,21,38-40]$.

Theobroma cacao L. is a plant native to the South American rainforest, belonging to the Malvaceae family [41]. It is considered that this plant has two large groups of origin according to their morphological and genetic characteristics and geographic location [42, 43]. The cocoa has great industrial importance since it is the raw material for chocolate [44]. Currently, the genotype CCN51 is the most commercialized clone in several countries due to its great productivity. In contrast, the Catongo genotype is used as a model of sustainability of the fungus Moniliophthora perniciosa [31, 45], which causes witches' broom disease in cocoa trees.

The CCN51 genotype is resistant to the fungus Moniliophthora perniciosa [45], and its phylloplane has twice as greater index of short glandular secreting trichomes than the Catongo genotype. A total of 41 proteins from leaf water washes (LWW) of the CCN51 identified by mass spectrometry revealed 28 plant proteins and 13 bacterial proteins [31]. This variation of the short glandular secreting trichomes index between the two genotypes may interfere in the microbial community of the phylloplane.

In this study, we propose that two contrasting genotypes for resistance to witches' broom have variations in the phylloplane microbiota. Therefore, using an independent culture approach, the total microbiome of the T. cacao phyloplane of the genotypes CCN51 and Catongo, were studied and characterized. We show that the differences in the index of glandular trichomes in the contrasting genotypes may affect the variety of bacterial microbioma symbiont of the phylloplane, and that the CCN51 genotype presents an exclusive genera with antagonistic potential against phytopathogens in relation to the catongo genotype, reinforcing its preference of agriculture for the cultivation and commercialization.

\section{Materials and methods}

\section{Plant material and DNA extraction}

A total of 300 plants of Theobroma cacao L. were cultivated in the greenhouse at CEPEC / CEPLAC (Cacao Research Center, Ilhéus-BA); 150 plants of the Catongo genotype and 150 of the CCN51 genotype. The plants were kept at room temperature and drip irrigation to avoid leaf washing. Seven pots of plants were randomly selected from each genotype to form the pool of the first biological sample, and another second group, also with seven pots of plants to form the pool of the second biological sample (Additional file 1: Figure S1). Therefore, the four biological samples (two from CCN51 and two from Catongo) underwent the extraction of the metagenomic DNA and analyzed in triplicates experimental (Additional file 2: Figure S2).

Young leaves were collected within 15 to 20 days after leaf primordium formation, and the metagenomic DNA extraction from the phylloplane was obtained through leaf water wash according to the method described by Shepherd [46]. Furthermore, other young leaves of the CCN51 and Catongo genotypes were collected with the purpose of observing the phylloplane topography and microbes using the Scanning Electron Microscope (SEM) Quanta 250 model (FEI Company).

For extraction of total DNA, each leaf was washed by immersion for $15 \mathrm{~s}$ in a beaker containing $100 \mathrm{ml}$ of distilled water maintained at temperature $8^{\circ} \mathrm{C}$. The microbiota was obtained from the LWW by filtering through a $0.22 \mu \mathrm{m}$ cellulose membrane to retain the microorganisms. Afterwards, the membrane was distributed in eppendorf tubes, flash-frozen in liquid nitrogen and freeze dried until complete elimination of water. $0.5 \mathrm{~g}$ of freeze-dried membrane was weighed and DNA was extracted using the PowerSoil ${ }^{\circ}$ DNA Isolation Kit (MoBio Laboratories, USA) according to the manufacturer's instructions. DNA quality was checked on $0.8 \%(w / v)$ agarose gel and concentration and purity measured using the Nanodrop (Thermo Scientific, USA). 


\section{Library construction and sequencing}

Bacterial 16S rRNA gene sequences of the V3-V4 hypervariable region were amplified by PCR using the $(341 F)$ forward and (805R) reverse primer [47]. PCR was performed in a final volume of $25 \mu \mathrm{L}$ containing the following: $2 \mu \mathrm{L}$ of template DNA, $12.5 \mu \mathrm{L}$ of HiFi HotStart ReadyMixPCR Kit (Kapa Biosystems) and $5 \mu \mathrm{L}$ of each oligonucleotide. Amplification was performed on the $\mathrm{Mx}$ 3005P apparatus (Agilent Technologies) under the following conditions: $95^{\circ} \mathrm{C}$ for $3 \mathrm{~min}$, followed by 25 cycles of $95^{\circ} \mathrm{C}$ for $30 \mathrm{~s}, 55^{\circ} \mathrm{C}$ for $30 \mathrm{~s}$ and $72^{\circ} \mathrm{C}$ for $30 \mathrm{~s}$, and a final elongation step at $72^{\circ} \mathrm{C}$ for $5 \mathrm{~min}$.

Amplicons from each biological replicate (3 amplifications for each of the four DNA extractions) were purified using the Agencourt $^{\circ}$ AMPure $^{\circ}$ XP system (Beckman Coulter, USA). The quality of the purified amplicons was evaluated in $1.5 \%$ agarose gel. A new PCR with Nextera XT Index Kit (FC-131-1002) with final volume of $50 \mu \mathrm{L}$ was performed in order to add the barcodes, using dual indexing strategy with two 8-base indices. The new amplification was performed under the same conditions as the previous PCR, except for the number of cycles (8). After quantification of the 12 samples using the Kapa Library Quantification kit (Additional file 3: Figure S3), the libraries were sequenced on the Illumina $\mathrm{MiSeq}^{\mathrm{ma}}$ equipment using the V3 kit (MiSeq ${ }^{\circ}$ Reagent - Illumina).

\section{Data analysis}

Raw bacterial sequence reads were initially subjected to the following preprocessing steps and quality controls: (i) $\leq 100$ nucleotides in length (not including sample barcodes) or more than $600 \mathrm{bp}$ were not considered and (ii) reads were trimmed at the beginning of a poor quality region with $10 \mathrm{bp}$ analyzed in FastQC [48] software with a Phred-score $\leq 20$. In subsequent screenings, files were processed using MeFit [49], to identify the best possible overlap region, with the least number of mismatching bases and carry out the merger.

Files were demultiplexed and end chimeras removed using the Quantitative Insights into Microbial Ecology (QIIME) [50] software package and operational taxonomic units (OTUs) were assigned by clustering the sequences with a threshold of $99 \%$ identity against the Greengen database version 13.8 16S rRNA [51]. OTUs, were assigned to "chloroplasts" and "mitochondria" before it was rarefied and served as input for alpha and beta diversity analysis, were filtered. The Qiime package generated rarefaction curves (richness of population analysis) and the calculation of the population diversity analysis estimator Chao1, as also, Alpha (within-sample richness) and beta diversity (between-sample dissimilarity) estimate. Using the GeanAIEx [52] software, the Principal Coordinates Analysis (PCoA) chart was plotted according to weighted UniFrac metrics ( $\beta$-diversity). To test whether there is a significant difference in bacterial community composition among genotypes CCN51 and Catongo, we used the analysis of similarity (ANOSIM) with 999 permutations [53].

\section{Results}

After pre-processing, filtering and rarefaction, the sequencing produced a total of 1.7 million reads of the V3-V4 variable region of the $16 \mathrm{~S}$ rRNA from leaf water washes of the two contrasting cacao genotypes for resistance of witches' broom disease, caused by $M$. perniciosa fungus. The average number of reads per sample was 95.398 , ranging from 42.068 to 346.420 . The identified bacteria were classified according to phylum, class, order, family, and genus (Additional file 4: Table S1). A total of 10 phyla and 73 genera were identified in the Catongo genotype and a total of 11 phyla and 91 genera in the CCN51 genotype (Fig. 1a). At the phylum level, proteobacteria is the most abundant phylum in the two genotypes, followed by cyanobacteria also in both genotypes and by bacteroidetes in the genotype Catongo (Fig. 1b) and actinobacteria in the CCN51 genotype (Fig. 1c).

The three dominant bacterial taxonomic classes in the Catongo and CCN51 genotypes were Gammaproteobacteria, Alphaproteobacteria and Actinobacteria (Fig. 2a and b). Among the orders identified (Fig. 1a), oceanospirillales, rickettsiales and enterobacteriales, were the three most abundant orders in both genotypes, 45.9, 21.6 and 9.6\% for Catongo and, 43.0, 20.1 and 6.6\% for CCN51, respectively.

At the family level, oceanospirillales (44.3\%) is the most abundant order in the CCN51 genotype, followed by rickettsiales (20.7\%) and enterobacteriales (6.8\%). Rickettsiales $(42.0 \%)$ is the most abundant order followed by enterobacteriales (18.7\%) and sphingomonadales $(4.9 \%)$, in the Catongo genotype. Comparison at genus level was carried out to reveal bacteria commonly or specifically identified in both genotypes, (Fig. 2c). Genotype CCN51 presented 33 genera of bacteria exclusive to its phylloplane in comparison to Catongo. The Stenotrophomonas genus was prevalent with $13.5 \%$ exclusively found in the CCN51 genotype, whereas the genus Sphingomonas prevailed with $75.3 \%$, in the Catongo genotype (Additional file 5: Table S2).

In terms of bacterial diversity, rarefaction curves generated from the library reads (42.000 reads per sample) based on a cutoff $99 \%$ sequence identity showed an asymptote for both genotypes, which tended to stabilize indicating sufficient sampling to capture most OTUs within communities (Fig. 3b). The graphic analysis showed the differences in biodiversity, because the genotype CCN51 represents the curves of the upper part of the figure, revealing that microbial communities from genotype CCN51 were more diverse than those from 

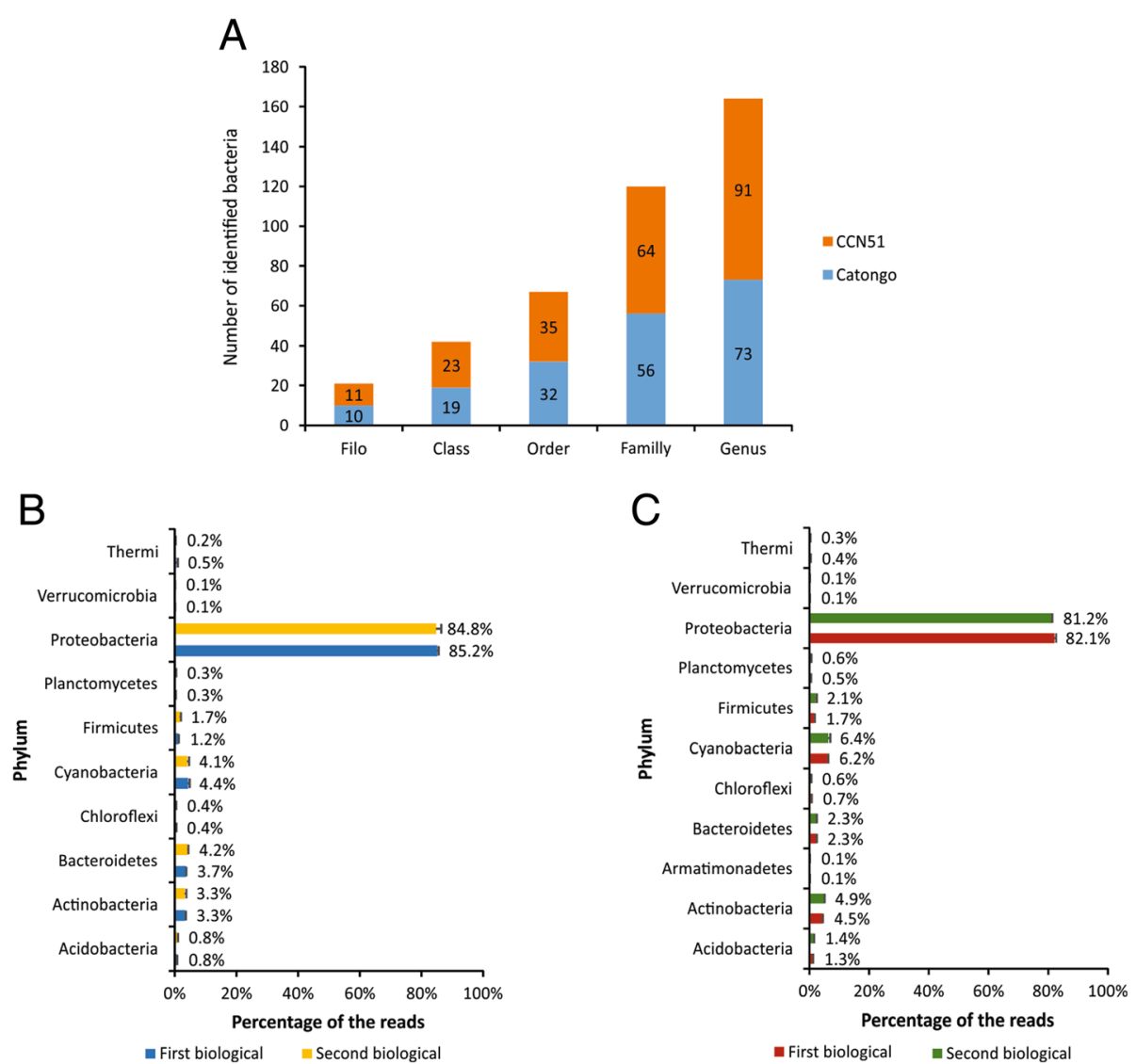

Fig. 1 Distribution of identified bacteria in leaf water washes of Theobroma cacao. a Distribution of the number of bacteria identified. Distribution of frequency of reads identified according to phylum: (b) Catongo genotype and (c) CCN51 genotype. Error bars indicate the standard deviation between the frequencies of three experimental samples of each biological sample

microbial communities from the genotype Catongo. The PCoA analysis based on weighted UniFrac metrics showed that the bacterial community were clustered per genotype (Fig. 3a), indicating the distinct bacterial diversity between CCN51 and Catongo. The ANOSIM results also showed that there is a significant difference in bacterial composition between genotypes CCN51 and Catongo (Global $R=0.996, P<0.05$ ).

Electron microscopy analysis of the leaves revealed that in the phylloplane many epiphytes occur in large bacterial aggregates, and fungi (Fig. 4). The field images provides spatial view of microbiome locations. Isolated bacterial cells have also been observed and some mixed aggregates can be found. The bacteria were visualized next to stomates, cell junctions and mainly in the foliar veins.

\section{Discussion}

Cocoa is a source of raw material for chocolate production and is cultivated in tropical and subtropical regions around the world [44]. Great losses in cacao production happen due to fungal diseases, such as witches' broom and frosty pod, caused by $M$. perniciosa and $M$. roreri [54], respectively.
These pathogens are hemibiobrophyc and start the infection process with spores deposited on the phylloplane from young cacao tissues (leaf and fruits). There is no effective chemical control after the invasion of the apoplast and onset of the parasitic phase of the disease $[55,56]$. The mechanisms of spore germination and pre-infection processes in contrasting resistance cacao genotypes has been analyzed [57]. Furthermore, the topography of the epicuticular wax layer [58], the short glandular secreting trichomes and the importance of water-soluble components of the phylloplane [31] have also been analyzed. M. perniciosa tends to have a relatively short epiphytic phase $[31,59]$ and requires few or no exogenous nutrients in this phase [60]. Thus, if biocontrol occurs at the epiphytic phase, antagonists that act as antibiotics (rather than competition) should be the most effective [61]. In this work, we analyze the composition and bacterial diversity of the phylloplane of CCN51 and Catongo cacao genotypes, resistant and susceptible to witches' broom respectively. DNA extracted from microorganisms recovered by filtration from leaf water washes was analyzed by metagenomic approach based on the sequencing of the v3-v4 hypervariable region from the $16 \mathrm{~S}$ rRNA. 

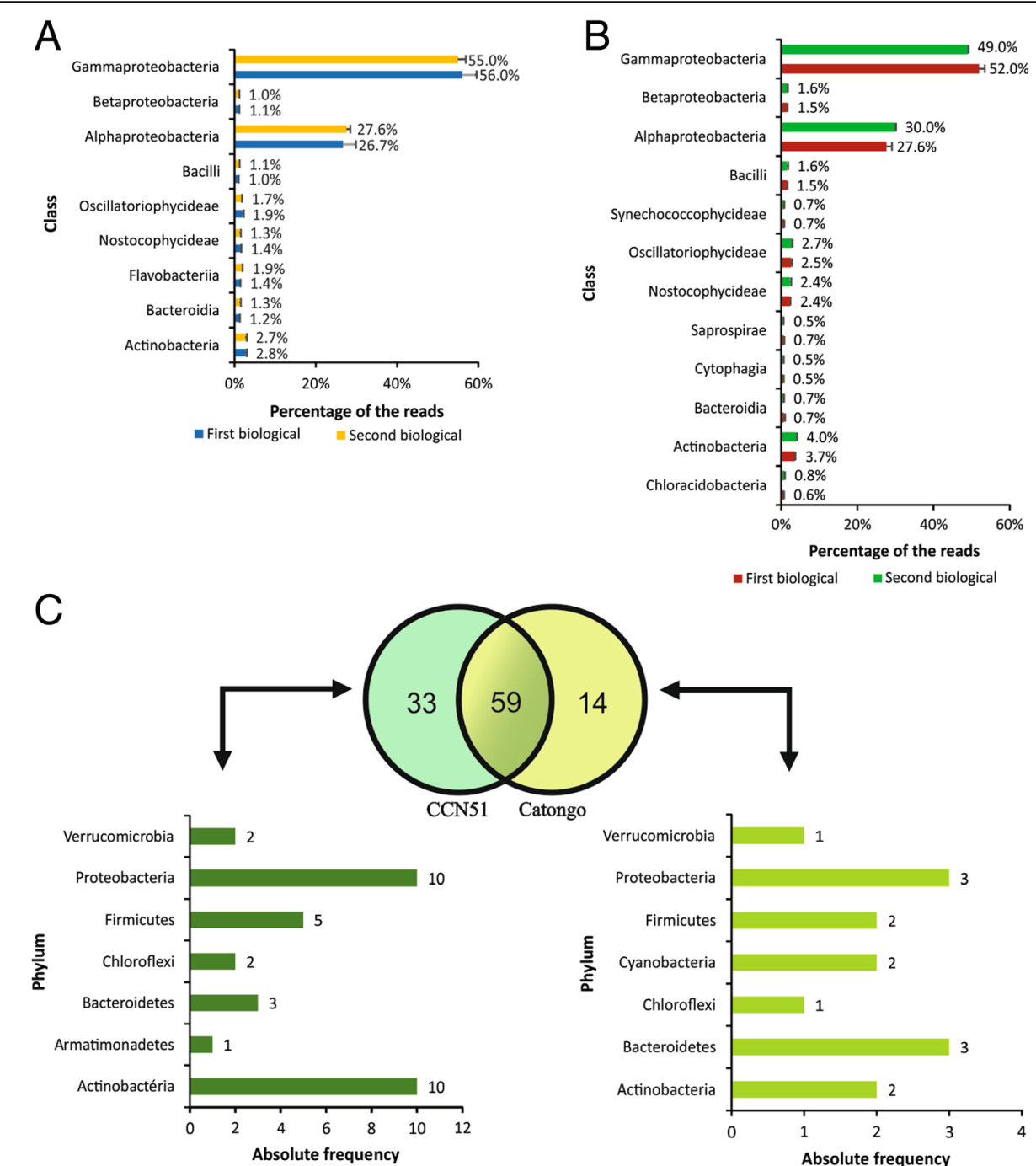

- First biological $\quad$ Second biological

Fig. 2 Distribution of the frequency of identified bacteria according to class in leaf water washes from contrasting cacao genotypes for $M$. perniciosa resistance. a susceptible Catongo genotype. $\mathbf{b}$ resistant CCN51 genotype. Only classes that represent $\geq 1 \%$ of the total population in at least one sample, are included. Error bars indicate the standard deviation between the frequencies of three experimental samples of each biological sample. c Comparison of the number of identified bacterial phylum in the phylloplane between two genotypes

Microbiome communities contained abundance of genera within the proteobacteria and cyanobacteria phylum, with prevalence of Candidatus Portiera in both genotypes (Additional file 4: Table S1). This genus presented a single species Candidatus Portiera aleyrodidarum sp. which provides amino acids and carotenoids [62] to its host Bemisia tabaci [63]. In the phylloplane, this microorganism may be acting symbiotically with $T$. cacao, participating in the organic metabolism with the contribution of amino acids tryptophan and also participating in the photosynthesis providing carotenoids $[62,64]$. Tryptophan may be involved in the cellular elongation of young leaves of T. cacao, as this amino acid is a precursor of indolylacetic acid, a growth hormone $[65,66]$.
Gammaproteobacteria is dominant in the taxonomic composition at class level of phylloplane communities of T. cacao (Fig. 2). It differs from tropical and temperate community structures already described. Phylloplane communities in Canadian forests were dominated by Alphaproteobacteria (68\%) [40], contrasting with 27\% in Malaysia [21] and 22.8\% in Panama [67] in tropical trees. However, percentages of Alphaproteobacteria in trees of tropical climates were similar to percentages found in $T$. cocoa. Some studies report that phylloplane bacteria vary among plants of different developmental stages and genotypes $[10,29]$. The bacterial diversity in the phylloplane appears to be as high as that presented in roots or in the human gut [10]. Others describe that microbial diversity and plant species may change according to the 

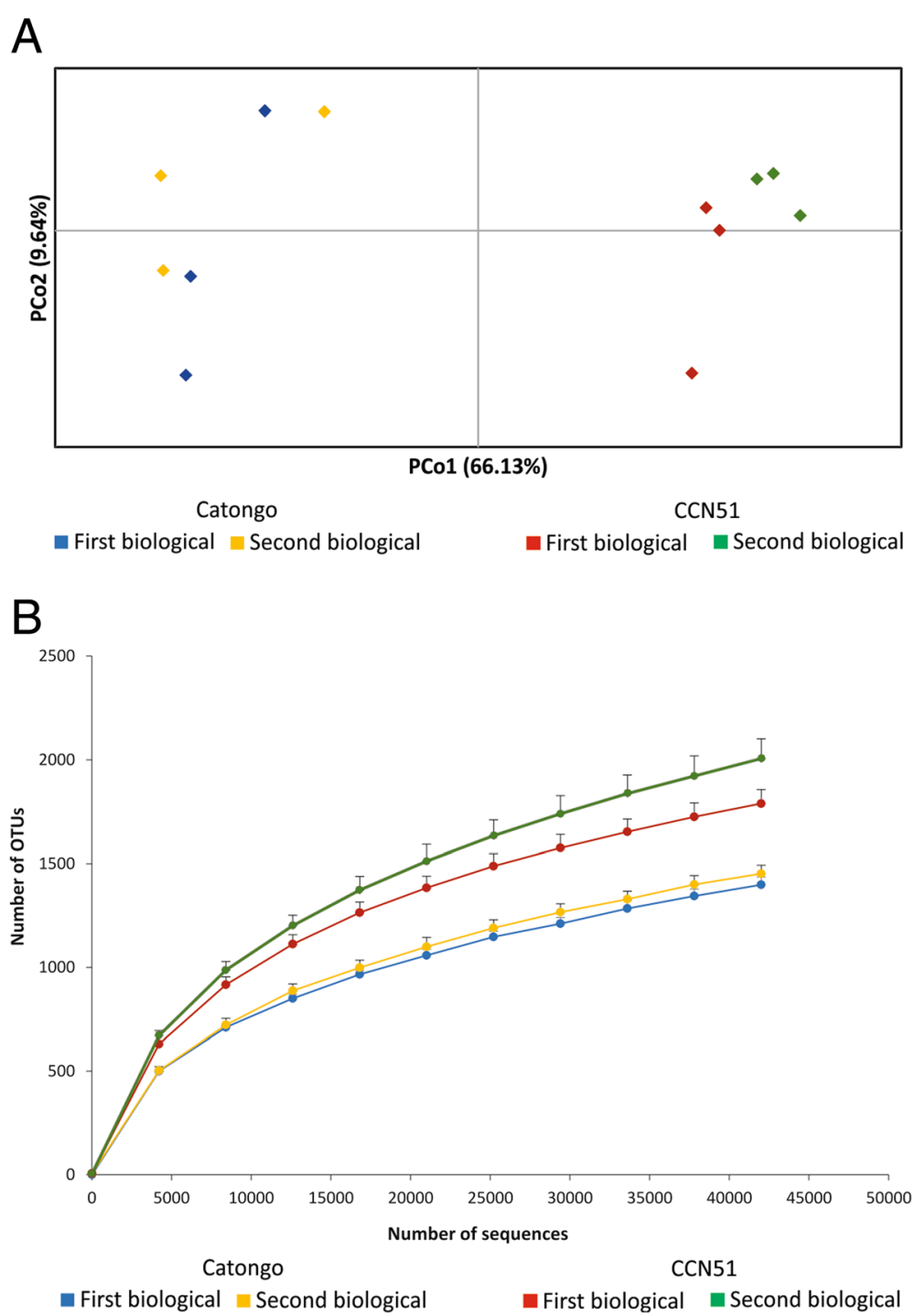

Fig. 3 PCoA plot and rarefaction curves determined for all 12 samples of microorganisms from phylloplane of the two contrasting cacao genotypes for M. perniciosa resistance. a Principal Coordinates Analysis (PCOA) between bacterial communities. b Rarefaction curves demonstrating species richness (Chaol) and diversity (PD entire tree)

environment, climate and geography [22, 26, 40, 68], revealing patterns of change in the phylloplane microbial communities of each species across geographically separated ecosystems. The large diversity of microbiota at the phylloplane may also influence plant evolution, as described by the hologenome theory. Both host and symbiont genomes can be transmitted from one generation to the next [11].

Sphingomonas (75.3\%), the predominant genus among the exclusive ones in Catongo, has a pigmentation which confers protection against UV radiation to the phylloplane [2], also assists in transportation of substrates (e.g. sugars, vitamins, siderophore) [22] and acts as regulator of stress-related responses, such as PhyR and EcfG [26]. Several members of the genus Sphingomonas isolated from plants (Arabidopsis thaliana, Acacia caven, Oryza sativa and Nicotiana tabacum) conferred protection in A. thaliana against Pseudomonas syringae and Xanthomonas campestris, reducing disease symptoms or diminishing pathogen growth in the phylloplane [69]. Sphingomonas melonis and Methylobacterium extorquens demonstrated a profound impact on the transcriptome of the plant Arabidopsis thaliana, researchers found that the expression of nearly 400 genes may be involved in the plant defense responses [70]. Nonetheless, Stenotrophomonas is the predominant genus (13.5\%) among the exclusive ones in CCN51 and it was reported as being characteristic from plant leaves (Chlorophytum comosum, Olea europaea and Dracaena draco), that grow in cold temperate climates [71]. The regulation system of pathogenicity factors (Rpf) 

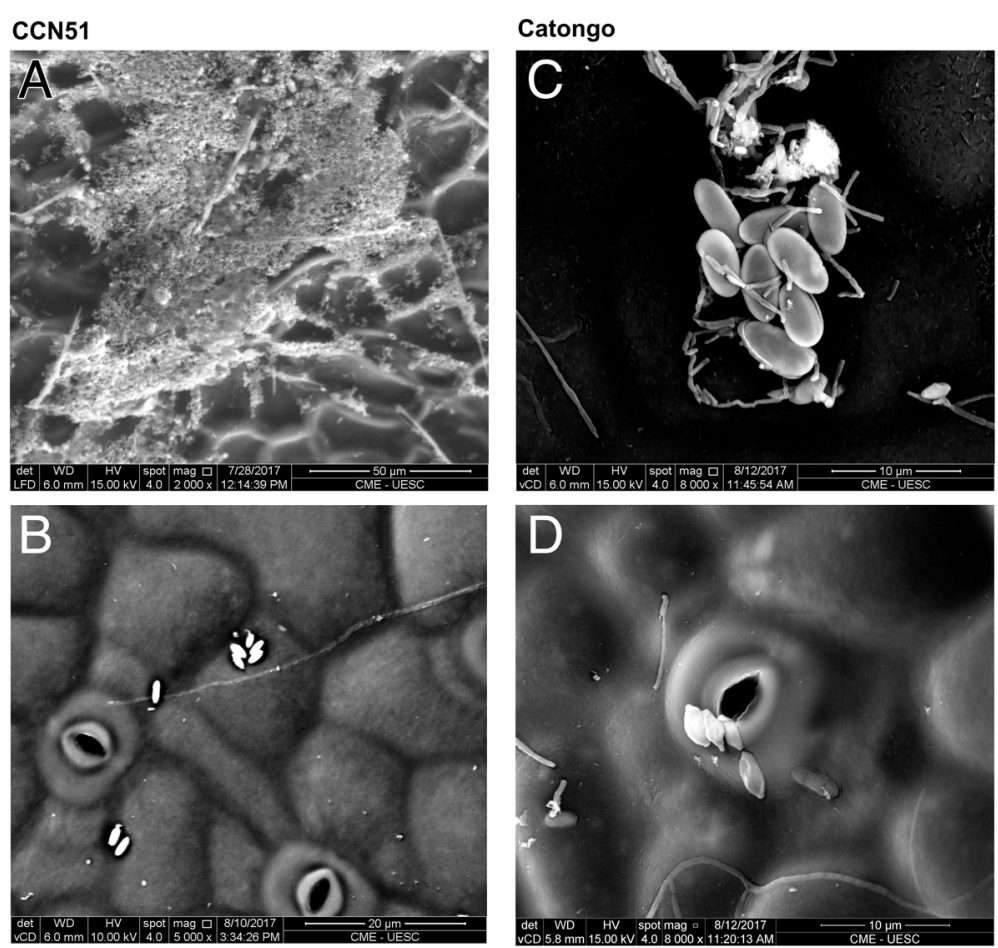

Fig. 4 Scanning electron microscopy analysis. a Adaxial surface of the CCN51 genotype. b Abaxial surface of the CCN51 genotype. c Adaxial surface of the Catongo genotype. $\mathbf{d}$ Abaxial surface of the Catongo genotype

and diffusible signal factor (DSF), are also conserved in this type of genus [72]. Other predominant genera among the exclusive ones in CCN51, were Lysobacter (5.89\%) and Paenibacillus (3.13\%). Lysobacter spp. has been shown to be important as biological control agents, producing both antibiotics and enzymes capable of degrading the cell walls from host fungi in Cucumis sativus and Solanum lycopersicum $[73,74]$. In contrast, a species of the genus Paenibacillus (P. peoriae), demonstrated a broad inhibition spectrum in several taxonomic groups of bacteria and fungi [75].

Rarefaction analyses (Fig. 3b) and PCoA analysis show that the total bacterial diversity in the genotype CCN51 phylloplane was larger in comparison to the Catongo genotype and the bacterial community is clustered as per the genotype type (Fig. 3a). According to the rarefaction curve, the CCN51 genotype of T. cacao showed higher OTUs than the Catongo genotype. The rarefaction curves trends to plateau suggests that a good coverage of the entire community of the phylloplane was achieved. The difference in the curve between the biological samples of the CCN51 genotype can be explained by the interval of 15 days between the collection of the first and second biological samples. The highest index of short glandular secreting trichomes that occur in the witch's broom-resistant CCN51 genotype compared to the susceptible Catongo [31], may affect the amount and variety of proteins and metabolites released into the phylloplane [2]. We believe that it might be the cause of the qualitative and quantitative differences in the microbial community of the two genotypes shown in the results. Furthermore, these phylloplane variations, due to plant metabolites and of the microbial community, together with variations in the topography of the phylosphere between genotypes (Fig. 4), strongly suggests that they may contribute to the differences in resistance to disease occurring between the CCN51 and Catongo genotypes [31].

Bacterial communities presented distinct colonization patterns in the T. cacao phylloplane (Fig. 4). Some studies have described that penetration of the germinal tube of the fungus $M$. perniciosa [76, 77], and colonization of other microorganisms, can occur at the base of the glandular trichoma, junctions of the cells, sites of lesions, stomata, and in the veins $[2,78]$, and may undergo changes at different seasons and age of the leaf. The diversity is lower during hot and dry months and higher during rainy and cold seasons [79]. In young leaves, communities are made up of a greater number of microorganisms relative to mature and senescent leaves, as well as at different seasons $[79,80]$. The formation of aggregates by bacteria may constitute between 30 and $80 \%$ of the total bacterial population in certain species of plants [81].

In the rice phylloplane, the microbiome presented greater diversity in cultivated and controlled plants in pots than those cultivated in the open field [82]. Bacterial community composition in phylloplane of Deschampsia 
antarctica at different locations in open fields, revealed significant differences [83]. The phylloplane and its microbial communities are interrelated [84] and can provide a structural and functional model microenvironment $[3,85]$ to understand plant-pathogen interactions and thus to select more resistant plants, which will contribute to the continuity of food production.

\section{Conclusions}

In this study, to the best of our knowledge, we describe for the first time the phylloplane bacterial communities of $T$. cacao. In addition, we performed the first evaluation of hosts identity and an analysis of diversity in two contrasting genotypes for witch's broom resistance. Proteobacteria is the most abundant phylum in the two genotypes, with prevalence of Candidatus Portiera in both. Genotype CCN51, resistant to the witch's broom, has a greater diversity of bacterial microbioma in comparison to Catongo and also greater amount of exclusive microorganisms in the phylloplane with antagonistic action against phytopathogens. The bacterial diversity among phylloplane populations are distinct between the genotypes according the PCoA analysis and validated by statistics ANOSIM that showed a significant difference in bacterial composition between genotypes CCN51 and Catongo. The study revealed the importance of epiphytic microbiome and may be a highly valuable tool in the process of biological control. The findings will be of great value for improving the understanding of the defense and interaction mechanisms that occur in the phylloplane.

\section{Additional files}

Additional file 1: Figure S1. Distribution of plants in the greenhouse. (A) Selected plants: green (first biological), red (second biological). (B) Panoramic photo of plants. (DOCX $2745 \mathrm{~kb}$ )

Additional file 2: Figure S2. Extraction of the metagenomic DNA in triplicates experimental. (A) First biological sample - CCN51. (B) First biological sample - Catongo. (C) Second biological sample - CCN51 and (D) Second biological sample - Catongo. (DOCX $151 \mathrm{~kb}$ )

Additional file 3: Figure S3. Quantification of libraries. (A) Electrophoresis on $1 \%(\mathrm{w} / \mathrm{V})$ agarose gel with the six standards, 12 libraries (quantified in triplicates) and three negative controls $-\mathrm{a}, \mathrm{b}$ and $\mathrm{c}$ : first biological sample - CCN51; d, e and f: first biological sample Catongo; g, h and i: second biological sample - CCN51; j, $\mathrm{k}$ and l: second biological sample - Catongo; NC: negative control. (B) Dissociation curve - a: libraries; b: negative control. (DOCX 307 kb)

Additional file 4: Table S1. Bacteria identified and classified according to phylum, class, order, family, and genus for in the genotypes CCN51 and Catongo, with a threshold of 99\% identity against the Greengen database version 13.8165 rRNA. (DOCX 19 kb)

Additional file 5: Table S2. Bacterial genera exclusive to the phylloplane of the genotypes CCN51 and Catongo. (DOCX 17 kb)

\section{Abbreviations}

ANOSIM: Analysis of similarity; DSF: Diffusible signal factor; LWW: Leaf water washes; NGS: Next-generation sequencing technology; OTUs: Operational taxonomic units; PCoA: Principal coordinates analysis; PCR: Polymerase chair reaction; QIIME: Quantitative Insights Into Microbial Ecology; Rpf: System of regulation of pathogenicity factors; SEM: Scanning Electron Microscope

\section{Acknowledgments}

We thank to Dr. Pedro Mangabeira for her help in electron microscopy and Dra. Cláudia Fortes for the revision of the english language.

\section{Funding}

Authors would like to acknowledge thank CAPES (PDSE2016-88881.132547 / 2016-01) for the funding of the sandwich bag. This work also was supported by FCT through funding of the DeST: Deep Semantic Tagger project, ref. PTDC/CCI-BIO/28685/2017, LaSIGE Research Unit, ref. UID/CEC/00408/2013 and BioISI, ref. ID/MULTI/04046/2013. The funding bodies had no role in the design of the study, in data collection, analysis or interpretation, or in writing the manuscript

\section{Availability of data and materials}

The data that support the findings of this study are available from the corresponding author upon reasonable request.

\section{Authors' contributions}

Conceived and designed the experiments: CPP, JOS. Contributed into experimental design: KPG. Preparation of the libraries and sequencing: JOS, KTdSEF. Extraction of metagenomic DNA and reagents: CPP, RPR. Scanning electron microscopy: PAOM. Metagenomic data analysis: FMC, RPMD, JOS. All authors had access to the data, reviewed and approved the final manuscript.

Ethics approval and consent to participate

Not applicable.

\section{Consent for publication}

Not applicable.

\section{Competing interests}

The authors declare that they have no competing interests.

\section{Publisher's Note}

Springer Nature remains neutral with regard to jurisdictional claims in published maps and institutional affiliations.

\section{Author details}

${ }^{1}$ Department of Biological Science, State University of Santa Cruz, Ilhéus, Bahia, Brazil. ${ }^{2}$ Cocoa Research Center, Ceplac/Cepec, Itabuna, BA, Brazil. ${ }^{3}$ BiolSI: Biosystems \& Integrative Sciences Institute, Faculdade de Ciências, Universidade de Lisboa, Lisbon, Portugal. ${ }^{4}$ LaSIGE, Faculdade de Ciências, Universidade de Lisboa, Lisbon, Portugal.

Received: 11 January 2018 Accepted: 14 November 2018

Published online: 23 November 2018

\section{References}

1. Bailey MJ, Lilley AK, Timms-Wilson TM, Spencer-Phillips PTN. Microbial ecology of aerial plant surfaces. Wallingford: CABl; 2006. p. 347.

2. Lindow SE, Brandl MT. Microbiology of the phyllosphere. Appl Environ Microbiol. 2003;69:1875-83.

3. Vorholt JA. Microbial life in the phyllosphere. Nat Rev. 2012:10:828-40.

4. Hallmann J, Quadt-Hallmann A, Mahaffee WF, Kloepper JW. Bacterial endophytes in agricultural crops. Can J Microbiol. 1997:43:895-914.

5. Ryffel F, Helfrich EJ, Kiefer P, Peyriga L, Portais JC, Piel J, Vorholt JA. Metabolic footprint of epiphytic bacteria on Arabidopsis thaliana leaves. ISME J. 2016;10(3):632-43.

6. van der Wal A, Leveau JH. Modelling sugar diffusion across plant leaf cuticles: the effect of free water on substrate availability to phyllosphere bacteria. Environ Microbiol. 2011;13:792-7.

7. Ueda H, Mitsuhara I, Tabata J, Kugimiya S, Watanabe T, Suzuki K, et al. Extracellular esterases of phylloplane yeast Pseudozyma antarctica induce defect on cuticle layer structure and water-holding ability of plant leaves. Appl Microbiol Biotechnol. 2015;99(15):6405-15.

8. Yeats $T H$, Rose JK. The formation and function of plant cuticles. Plant Physiol. 2013;163(1):5-20. 
9. Lymperopoulou DS, Adams RI, Lindow SE. Contribution of vegetation to the microbial composition of nearby outdoor air. Appl Environ Microbiol. 2016; 82(13):3822-33.

10. Berlec A. Novel techniques and findings in the study of plant microbiota: search for plant probiotics. Plant Sci. 2012;193-194:96-102.

11. Zilber-Rosenberg I, Rosenberg E. Role of microorganisms in the evolution of animals and plants: the hologenome theory of evolution. FEMS Microbiol Rev. 2008;32(5):723-35.

12. Kadivar $\mathrm{H}$, Stapleton AE. Ultraviolet radiation alters maize phyllosphere bacterial diversity. Microb Ecol. 2003;45(4):353-61.

13. Yutthammo C, Thongthammachat N, Pinphanichakarn P, Luepromchai E. Diversity and activity of $\mathrm{PAH}$-degrading bacteria in the phyllosphere of ornamental plants. Microb Ecol. 2010;59(2):357-68.

14. Suda W, Nagasaki A, Shishido M. Powdery mildew-infection changes bacterial community composition in the phyllosphere. Microbes Environ. 2009;24(3):217-23.

15. Andrews JH, Harris RF. The ecology and biogeography of microorganisms on plant surfaces. Annu Rev Phytopathol. 2000;38:145-80.

16. Peñuelas J, Terradas J. The foliar microbiome. Trends Plant Sci. 2014;19(5): 278-80.

17. Redford AJ, Bowers RM, Knight R, Linhart Y, Fierer N. The ecology of the phyllosphere: geographic and phylogenetic variability in the distribution of bacteria on tree leaves. Environ Microbiol. 2010;12(11):2885-93.

18. Yeonhwa J, Jin KC, Hoseong C, Hyosub C, Sen L, Won KC. Bacterial communities in the Phylloplane of Prunus species. J Basic Microbiol. 2014; 55(4):504-8.

19. Reddy AP, Simmons CW, D'haeseleer P, Khudyakov J, Burd H, Hadi M, et al. Discovery of microorganisms and enzymes involved in high-solids decomposition of rice straw using metagenomic analyses. PLoS One. 2013; 8(10):e77985.

20. Pinto C, Pinho D, Sousa S, Pinheiro M, Egas C, Gomes AC. Unravelling the diversity of grapevine microbiome. PLoS One. 2014;9(1):e85622.

21. Kim M, Singh D, Lai-Hoe A, Go R, Abdul Rahim R, Ainuddin AN. Distinctive phyllosphere bacterial communities in tropi cal trees. Microb Ecol. 2012; 63(3):674-81.

22. Delmotte N, Knief C, Chaffron S, Innerebner G, Roschitzki B, Schlapbach R, et al. Community proteogenomics reveals insights into the physiology of phyllosphere bacteria. Proc Natl Acad Sci U S A. 2009;106(38):16428-33.

23. Redford AJ, Fierer N. Bacterial succession on the leaf surface: a novel system for studying successional dynamics. Microb Ecol. 2009:58(1):189-98.

24. Finkel OM, Burch AY, Elad T, Huse SM, Lindow SE, Post AF. Distance-decay relationships partially determine diversity patterns of phyllosphere bacteria on Tamarix trees across the Sonoran Desert [corrected]. Appl Environ Microbiol. 2012;78(17):6187-93

25. Bulgarelli D, Schlaeppi K, Spaepen S, Ver Loren van Themaat E, SchulzeLefert P. Structure and functions of the bacterial microbiota of plants. Annu Rev Plant Biol. 2013:64:807-38.

26. Rastogi $\mathrm{G}$, Coaker GL, Leveau JH. New insights into the structure and function of phyllosphere microbiota through high-throughput molecular approaches. FEMS Microbiol Lett. 2013;348(1):1-10

27. Cindy HW, Bernard SM, Gary LA, Wilfred C. Developing microbe-plant interactions for applications in plant-growth promotion and disease control, production of useful compounds, remediation and carbon sequestration. Microb Biotechnol. 2009;2(4):428-40.

28. Abril AB, Torres PA, Bucher EH. The importance of phyllosphere microbial populations in nitrogen cycling in the Chaco semi-arid woodland. J Trop Ecol. 2005:21(1):103-7.

29. Peñuelas J, Rico L, Ogaya R, Jump AS, Terradas J. Summer season and longterm drought increase the richness of bacteria and fungi in the foliar phyllosphere of Quercus ilex in a mixed Mediterranean forest. Plant Biol (Stuttg). 2012;14(4):565-75.

30. Rasche F, Marco-Noales E, Velvis H, van Overbeek LS, Lopez MM, van Elsas JD, Sessitsch A. Structural characteristics and plant-beneficial effects of bacteria colonizing the shoots of field grown conventional and genetically modified T4-lysozyme producing potatoes. Plant Soil. 2006;289(1):123-40.

31. Almeida DSM, Gramacho KP, Cardoso THS, Micheli F, Alvim FC, Pirovani CP. Cacao phylloplane: the first battlefield against Moniliophthora perniciosa, which causes witches' broom disease. Phytopathology. 2017;107(7):864-71.

32. Freire L, Santana JO, de Sousa AO, dos Santos JB, de Oliveira IB, Alvima FC, et al. TCPHYLL, a cacao phylloplanin expressed in young tissues and glandular trichomes. Physiol Mol Plant Pathol. 2017;100:126-35.
33. Kroumova AB, Shepherd RW, Wagner GJ. Impacts of T-Phylloplanin gene knockdown and of Helianthus and Datura phylloplanins on Peronospora tabacina spore germination and disease potential. Plant Physiol. 2007;144(4):1843-51.

34. van der Heijden MG, Hartmann M. Networking in the plant microbiome. PLoS Biol. 2016;14(2):e1002378.

35. Caporaso JG, Lauber CL, Walters WA, Berg-Lyons D, Huntley J, Fierer N. Ultra-high-throughput microbial community analysis on the Illumina HiSeq and MiSeq platforms. ISME J. 2012;6(8):1621-4.

36. Mardis ER. Next-generation DNA sequencing methods. Annu Rev Genomics Hum Genet. 2008;9:387-402

37. Kembel SW, Eisen JA, Pollard KS, Green JL. The phylogenetic diversity of metagenomes. PLoS One. 2011;6(8):e23214.

38. Degnan $\mathrm{P}$, Ochman $\mathrm{H}$. Illumina-based analysis of microbial community diversity. ISME J. 2012;6(1):183-94.

39. Lundberg DS, Lebeis SL, Paredes SH, Yourstone S, Gehring J, Malfatti S, et al. Defining the core Arabidopsis thaliana root microbiome. Nature. 2012; 488(7409):86-90.

40. Laforest-Lapointe I, Messier C, Kembel SW. Host species identity, site and time drive temperate tree phyllosphere bacterial community structure. Microbiome. 2016;4(1):27.

41. Sounigo O, Lachenaud P, Bastide P, Cilas C, N'Goran J, Lanaud C. Assessment of the value of doubled haploids as progenitors in cocoa (Theobroma cacao L.) breeding. J Appl Genet. 2003;44(3):339-53.

42. Almeida AF, Valle RR. Ecophysiology of the cacao tree. Braz J Plant Physiol. 2007:19(4):425-48

43. Rosário M, Perrucho T, Fowler RL, Sales JC. Cacau: história e evolução no mundo. Ilhéus: Ceplac; 1978. p. 46.

44. Purdy LH, Schmidt RA. Status of cacao witches'broom: biology, epidemiology, and management. Annu Rev Phytopathol. 1996;34:573-94.

45. Lopes UV, Monteiro WR, Pires UL, Clement D, Yamada MM, Gramacho KP. Cacao breeding in Bahia, Brazil - strategies and results. Crop Breed Appl Biot. 2011:1:73-81

46. Shepherd RW, Bass WT, Houtz RL, Wagner GJ. Phylloplanins of tobacco are defensive proteins deployed on aerial surfaces by short glandular trichomes Plant Cell Online. 2005;17(6):1851-61.

47. Herlemann DP, Labrenz M, Jurgens K, Bertilsson S, Waniek JJ, Andersson AF. Transitions in bacterial communities along the $2000 \mathrm{~km}$ salinity gradient of the Baltic Sea. ISME J. 2011:5(10):1571-9.

48. Andrews S. Fastqc a quality control tool for high throughput sequence data. 2010. Available form: http://www.bioinformatics.babraham.ac.uk/ projects/fastqc.

49. Parikh HI, Koparde VN, Bradley SP, Buck GA, Sheth NU. MeFiT: merging and filtering tool for illumina paired-end reads for 165 rRNA amplicon sequencing. BMC Bioinformatics. 2016;17(1):491.

50. Caporaso JG, Kuczynski J, Stombaugh J, Bittinger K, Bushman FD, Costello EK, et al. QIIME allows analysis of high-throughput community sequencing data. Nat Methods. 2010;7(5):335-6.

51. DeSantis TZ, Hugenholtz P, Larsen N, Rojas M, Brodie EL, Keller K, et al. Greengenes, a chimera-checked 165 rRNA gene database and workbench compatible with ARB. Appl Environ Microbiol. 2006;72(7):5069-72.

52. Peakall R, Smouse PE. GenAlEx 6.5: genetic analysis in excel. Population genetic software for teaching and research-an update. Bioinformatics. 2012; 28:2537-9.

53. Clarke KR. Non-parametric multivariate analysis of changes in community structure. Aust J Ecol. 1993:18(1):117-43.

54. Aime MC, Phillips-Mora W. The causal agents of witches' broom and frosty pod rot of cacao (chocolate, Theobroma cacao) form a new lineage of Marasmiaceae. Mycologia. 2005;97(5):1012-22.

55. Ceita G, Macêdo JNA, Bomfim T, Alemanno L, Gesteira AS, Micheli F, et al. Involvement of calcium oxalate degradation during programmed cell death in Theobroma cacao tissues triggered by the hemibiotrophic fungus Moniliophthora perniciosa. Plant Sci. 2007:173(2):106-17.

56. Sena K, Alemanno L, Gramacho KP. The infection process of Moniliophtora perniciosa in cacao. Plant Pathol. 2014;63:1272-81.

57. Mares JH, Gramacho KP, Santos EC, Santiago AS, Silva EMA, Alvim FC. Protein profile and protein interaction network of Moniliophthora perniciosa basidiospores. BMC Microbiol. 2016;16(1):120.

58. Nyadanu D, Akromah R, Adomako B, Kwoseh C, Dzahini-Obiatey H, Lowor ST. Host plant resistance to phytophthora pod rot in cacao (Theobroma cacao L): the role of epicuticular wax on pod and leaf surfaces. Int J Bot. 2012;8(1):13-21. 
59. Leite HA, Silva AB, Gomes FP, Gramacho KP, Faria JC, de Souza JT, et al. Bacillus subtilis and Enterobacter cloacae endophytes from healthy Theobroma cacao L. trees can systemically colonize seedlings and promote growth. Appl Microbiol Biotechnol. 2013;97(6):2639-51.

60. Andrews JH. Biological control in the phyllosphere. Annu Rev Phytopathol. 1992;30:603-35

61. Rytter JL, Lukezic FL, Craig R, Moorman GW. Biological control of geranium rust by Bacillus subtilis. Phytopathology. 1989;79:367-70.

62. Santos-Garcia D, Farnier P, Beitia F, Zchori-Fein E, Vavre F, Mouton L, et al. Complete genome sequence of "Candidatus Portiera aleyrodidarum" BT-

QVLC, an obligate symbiont that supplies amino acids and carotenoids to Bemisia tabaci. J Bacteriol. 2012;194(23):6654-5.

63. Sudakaran S, Kost C, Kaltenpoth M. Symbiont acquisition and replacement as a source of ecological innovation. Trends Microbiol. 2017;25(5):375-90.

64. Delgado-Vargas F, Jiménez AR, Paredes-López O. Natural pigments: carotenoids, anthocyanins, and betalains - characteristics, biosynthesis, processing, and stability. Crit Rev Food Sci Nutr. 2000:40(3):173-289.

65. Kawaguchi M, Syono K. The excessive production of indole-3-acetic acid and its significance in studies of the biosynthesis of this regulator of plant growth and development. Plant Cell Physiol. 1996;37(8):1043-8.

66. Mano Y, Nemoto K. The pathway of auxin biosynthesis in plants. J Exp Bot. 2012;63(8):2853-72.

67. Kembel SW, O'Connorb TK, Arnoldb HK, Hubbell SP, Wrightd SJ, Greenb JL. Relationships between phyllosphere bacterial communities and plant functional traits in a neotropical forest. PNAS. 2014;111(38):13715-20.

68. Ryan RP, Fouhy Y, Garcia BF, Watt SA, Niehaus K, Yang L, et al. Interspecies signalling via the Stenotrophomonas maltophilia diffusible signal factor influences biofilm formation and polymyxin tolerance in Pseudomonas aeruginosa. Mol Microbiol. 2008;68(1):75-86.

69. Innerebner G, Knief C, Vorholt JA. Protection of Arabidopsis thaliana against leaf-pathogenic Pseudomonas syringae by Sphingomonas strains in a controlled model system. Appl Environ Microbiol. 2011;77:3202-10.

70. Vogel C, Bodenhausen N, Gruissem W, Vorholt JA. The Arabidopsis leaf transcriptome reveals distinct but also overlapping responses to colonization by phyllosphere commensals and pathogen infection with impact on plant health. New Phytol. 2016;212:192-207.

71. Ortega RA, Mahnert A, Berg C, Müller H, Berg G. The plant is crucial: specific composition and function of the phyllosphere microbiome of indoor ornamentals. FEMS Microbiol Ecol. 2016;92(12):1-12.

72. Müller T, Ruppel S. Progress in cultivation-independent phyllosphere microbiology. FEMS Microbiol Ecol. 2014;87(1):2-17.

73. Sullivan RF, Holtman MA, Zylstra GJ, White JF, Kobayashi DY. Taxonomic positioning of two biological control agents for plant diseases as Lysobacter enzymogenes based on phylogenetic analysis of $16 \mathrm{~S}$ rDNA, fatty acid composition and phenotypic characteristics. J Appl Microbiol. 2003;94(6):1079-86.

74. Folman LB, Postma J, van Veen JA. Characterisation of Lysobacter enzymogenes (Christensen and cook 1978) strain 3.1T8, a powerful antagonist of fungal diseases of cucumber. Microbiol Res. 2003;158(2):107-15.

75. von der Weid I, Alviano DS, Santos AL, Soares RM, Alviano CS, Seldin L. Antimicrobial activity of Paenibacillus peoriae strain NRRL BD-62 against a broad spectrum of phytopathogenic bacteria and fungi. J Appl Microbiol. 2003;95(5):1143-51.

76. Sreenivasan TN, Sabydeen S. Modes of penetration of young cocoa leaves by Crinipellis perniciosa. Am Phytopathol Soc. 1989;73(6):478-81.

77. Pires AB, Gramacho KP, Silva DC, Góes-Neto A, Silva MM, Muniz-Sobrinho JS, et al. Early development of Moniliophthora perniciosa basidiomata and developmentally regulated genes. BMC Microbiol. 2009;9:158.

78. Caicedo JC, Villamizar S, Ferro MIT, Kupper KC, Ferro JA. Bacteria from the citrus phylloplane can disrupt cell-cell signalling in Xanthomonas citri and reduce citrus canker disease severity. Plant Pathology. 2016;65(5):782-91.

79. Ercolani GL. Distribution of epiphytic bacteria on olive leaves and the influence of leaf age and sampling time. Microb Ecol. 1991;21:35-48.

80. Thompson IP, Bailey MJ, Fenlon JS, Fermor TR, Lilley AK, Lynch JM, et al. Quantitative and qualitative seasonal changes in the microbial community from the phyllosphere of sugar beet (Beta vulgaris). Plant Soil. 1993;150:177-91.

81. Monier JM, Lindow SE. Differential survival of solitary and aggregated bacterial cells promotes aggregate formation on leaf surfaces. PNAS. 2003; 100(26):15977-82.

82. Venkatachalam S, Ranjan K, Prasanna R, Ramakrishnan B, Thapa S, Kanchan A. Diversity and functional traits of culturable microbiome members, including cyanobacteria in the rice phyllosphere. Plant Biol. 2016;18:627-37.
83. Cid FP, Inostroza NG, Graether SP, Bravo LA, Jorquera MA. Bacterial community structures and ice recrystallization inhibition activity of bacteria isolated from the phyllosphere of the Antarctic vascular plant Deschampsia antarctica. Polar Biol. 2017:40:1319-31.

84. Vandenkoornhuyse P, Quaiser A, Duhamel M, Le Van A, Dufresne A. The importance of the microbiome of the plant holobiont. New Phytol. 2015; 206:1196-206

85. Thapa S, Prasanna R. Prospecting the characteristics and significance of the phyllosphere microbiome. Ann Microbiol. 2018;68:229-45.

\section{Ready to submit your research? Choose BMC and benefit from:}

- fast, convenient online submission

- thorough peer review by experienced researchers in your field

- rapid publication on acceptance

- support for research data, including large and complex data types

- gold Open Access which fosters wider collaboration and increased citations

- maximum visibility for your research: over $100 \mathrm{M}$ website views per year

At $\mathrm{BMC}$, research is always in progress.

Learn more biomedcentral.com/submissions 